\title{
Stat3 and CCAAT/enhancer binding protein beta (C/EBP-beta) regulate Jab1/CSN5 expression in mammary carcinoma cells
}

Terry J Shackleford ', Qingxiu Zhang ${ }^{1}$, Ling Tian', Thuy T Vu', Anita L Korapati', Angela M Baumgartner ${ }^{1}$, Xiao-Feng Le ${ }^{2}$, Warren $\mathrm{S}$ Liao $^{2}$ and Francois $X$ Claret $^{1^{*}}$

\begin{abstract}
Introduction: The c-Jun coactivator, Jun activation-domain binding protein 1 (Jab1) also known as the fifth component of the COP9 signalosome complex (CSN5), is a novel candidate oncogene whose aberrant expression contributes to the progression of breast carcinoma and other human cancers. The mechanism of Jabl gene expression and its deregulation in cancer cells remains to be identified. We therefore investigated the transcriptional regulatory mechanisms of Jab1 expression in human breast carcinoma cells.

Methods: To identify potential regulators of Jab1 transcription, we cloned the $5^{\prime}$ upstream region of the human Jabl gene and mapped its transcriptional start site. We identified binding sequences for the CCAAT/enhancer binding protein (C/EBP) and GATA, as well as a signal transducer and activator of transcription-3 (Stat3) consensus sequence overlapping the C/EBP site, using 5'- deletion analysis and a gene reporter assay. Mutational analysis of these binding sites was performed to confirm their roles in promoting Jab1 transcription in breast cancer cells. We further confirmed these binding sites using electrophoretic mobility shift assays (EMSAs) and chromatin immunoprecipitation (ChIP) assays. We also analyzed whether the siRNA-mediated inactivation of Stat3 and Src could reduce Jab1-promoter activity and whether interleukine-6 (IL-6) could mediate increased Jab1 expression through Stat3 signaling.
\end{abstract}

Results: We identified binding sequences for C/EBP, GATA, as well as a Stat3 consensus sequence overlapping the C/EBP site in the promoter region of Jab1. C/EBP-beta2 is a potential transcriptional activator of Jab1 and mutation of the C/EBP/Stat3 binding site significantly reduced Jab1-promoter activity. In addition, inhibiting Stat3 significantly reduced Jab1-promoter activation. EMSA and ChIP assays confirmed that C/EBP, GATA1 and Stat3 bind to Jab1 promoter in breast carcinoma cells. We also found that Src, an activator of Stat3, is involved in Jab1-promoter activation. siRNA knockdown of Src reduced the Jab1-promoter activity, similar to the results seen when Stat3 was inhibited in breast carcinoma cells. Interestingly, reactivation of Stat3 in normal mammary epithelial cells (MCF-10A, MCF-10F) is sufficient to reactivate Jab1 expression. Treatment with the cytokine IL-6 resulted in increased Jab1 expression that was blocked by inhibition of Stat3.

Conclusions: These findings reveal a novel mechanism of Jabl gene regulation and provide functional and mechanistic links between the Src/Stat3 and IL-6/Stat3 signaling axes that are involved in the activation of Jab1 transcription and regulation of this novel oncogenic protein.

\footnotetext{
* Correspondence: fxclaret@mdanderson.org

'Department of Systems Biology, Unit 950, University of Texas - MD Anderson Cancer Center, 1515 Holcombe Boulevard, Houston, TX 77030, USA

Full list of author information is available at the end of the article
} 


\section{Introduction}

c-Jun activation domain-binding protein-1 (Jab1) is a multifunctional protein that regulates cell proliferation and oncogenesis. Since its identification as a c-Jun coactivator [1], Jab1 has been found to be an integral component of the COP9 signalosome (CSN) complex, a multifunctional protein complex involved in modulating signal transduction, gene transcription, and protein stability [2-4]. Jab1 is the fifth subunit of the CSN and is also referred to as CSN5. One of the most recognized functions of the CSN is the deneddylation of the cullinRING-ubiquitin ligase (CRL) and this function is reliant on the Jab1 MPN domain metalloenzyme (JAMM) motif that serves as the catalytic center [5,6]. Jab1 exists not only as a member of the CSN holocomplex and smaller CSN complexes, but also as a monomer with a number of different unique protein interactions and functions outside of the CSN.

Jab1 functionally inactivates several key negative regulatory proteins by affecting their subcellular localization, degradation, phosphorylation, and deneddylation, thereby acting as a positive regulator of cellular proliferation. Through these interactions, Jab1 plays a crucial role in the inactivation of several key tumor suppressors, including cyclin-dependent kinase inhibitor p2 $7^{\mathrm{Kip} 1}$, p53, and Smad4/7 [7-10]. It can also interact with several important intracellular signaling molecules including hypoxia inducible factor- 1 alpha (HIF-1 $\alpha$ ), macrophage migration inhibitory factor (MIF), E2F1, and cullin 1 (CUL-1) [11,12].

Abnormal overexpression of Jab1 has been detected in several types of cancer in humans and in some cases correlates with poor prognosis and low-level expression of p27 [13-18]. However, the molecular mechanism for up-regulation of Jab1 in cancer cells is still unclear. Our studies have shown that Jab1 and p27 protein levels are inversely correlated in invasive breast carcinoma specimens and that Jab1 is highly expressed in breast tumor samples relative to paired normal-tissue samples [14]. Jab1, along with the oncogene Myc, reside on the frequently amplified region on chromosome 8 and were identified to induce a wound signature in human breast cancer cells [19]. Further investigations identified the isopeptidase activity of Jab1 to be critical for its ability to promote transformation and progression in breast epithelial cells and inhibition of this activity is sufficient to block breast cancer progression driven by MYC and RAS [20]. These findings suggest that Jab1 is an important regulator in cancer development and preclinical studies suggest that inhibition of Jab1 delays tumor growth [14].

Given the frequency of Jab1 overexpression in human cancers and its potential role in the development of cancer, identifying the mechanism by which Jab1 overexpression occurs would be of great interest. The extent to which Jab1 amplification on chromosome 8q is responsible for its frequent overexpression in cancer has not yet been investigated. However, additional mechanisms of regulation through transcriptional control are likely to also be of importance and may link its regulation to upstream signaling pathways. We hypothesize that overexpression of Jab1 in breast cancer can be attributed to an increase in transcriptional activity over that seen in normal tissue. We therefore studied the transcriptional regulation of Jab1 in breast cancer cells. In this present study, we describe the cloning and characterization of the human $J a b 1$ promoter. We also identify a region whereby CCAAT/enhancer binding protein-beta (C/EBP- $\beta)$, signal transducer and activator of transcription-3 (Stat3), and GATA1 induce $J a b 1$ transcription and identify a potential upstream oncogenic signaling molecule that may be key to the regulation of Jab1 expression in cancer. The region we describe here has also recently been identified by another group to contain a $\mathrm{T}$-cell transcription factor (TCF)- 4 and Sp1 binding site that was found to be important for transcription and activated by human epidermal growth factor receptor (HER)-2 activation of the $\mathrm{AKT} / \beta$-catenin pathway [21], which points to the importance of this region in driving the transcription of $J a b 1$ and possibly linking its expression to potent oncogenic signaling pathways.

\section{Materials and methods}

\section{Cell lines, reagents and antibodies}

The human breast cancer cell lines, MCF7, MDA-MB468, MDA-MB-231, BT-474, ZR-75-1, BT-549, MDA$\mathrm{MB}-453, \mathrm{~T} 47 \mathrm{D}$ and non-tumorigenic human breast epithelial MCF-10A, MCF-10F, HMEC, and 184A, were purchased from the American Type Culture Collection (Manassas, VA, USA). None were derived directly from tumor tissue for the purposes of this study. MCF7 cells were grown in DMEM. Breast cancer cells were grown in RPMI medium supplemented with 10\% FBS. MCF$10 \mathrm{~A}$ and MCF-10F cells were grown in 50\% DMEM, $50 \%$ F- 12 medium supplemented with $5 \%$ horse serum, 100 units $/ \mathrm{ml}$ penicillin, $100 \mu \mathrm{g} / \mathrm{ml}$ streptomycin, $10 \mu \mathrm{g} /$ $\mathrm{ml}$ insulin, $100 \mathrm{ng} / \mathrm{ml}$ cholera toxin, $0.5 \mu \mathrm{g} / \mathrm{ml}$ hydrocortisone, $20 \mathrm{ng} / \mathrm{ml}$ recombinant human epidermal growth factor, and $1 \mathrm{mM} \mathrm{CaCl}_{2}$. The following antibodies were used in the study: C/EBP- $\alpha$ (N-19), C/EBP- $\beta$ (C-19), GATA-1 (H-200), and Stat3 (C-20) (Santa Cruz Biotechnology, Santa Cruz, CA, USA). The following antibodies were obtained from Cell Signaling (Danvers, MA, USA): Src, Phospho-Stat3(Y705), $\beta$-Tubulin, and $\beta$-actin. AntiFlag was obtained from Sigma-Aldrich (St. Louis, MO, USA). IL-6 was obtained from Invitrogen (Carlsbad, CA, USA) and used at $40 \mathrm{ng} / \mathrm{mL}$. The Stattic inhibitor (Sigma, St. Louis, MO, USA) was used at $20 \mathrm{nM}$. 


\section{Primer extension}

An antisense primer, P1 was designed 5' of the ATG translation site of the Jab1 gene and end-labeled with T4 polynucleotide kinase and ${ }^{32} \mathrm{P}-\gamma$-ATP, followed by purification using Nu-Clean D25 columns (Shelton ScientificIBI, Peosta, IA, USA). Total RNA was isolated from MDA-MD-231 cells using TRIzol reagent (Invitrogen, Carlsbad, CA, USA), and $20 \mu \mathrm{g}$ of RNA was hybridized with $1 \times 10^{6}$ c.p.m. of ${ }^{32}$ P-labeled P1 oligonucleotide. The protocol for the Primer Extension System-AMV Reverse Transcriptase (Promega, Madison, WI, USA) was followed. The size of the extended product was determined by electrophoresis on a $6 \%$ polyacrylamide gel containing $6 \mathrm{M}$ urea. To determine the size of the primer extended fragment, the labeled Promega marker and a sequencing reaction with Jab1 cDNA as template and primer P1 using the SequiTherm Excel II DNA Sequencing Kit (Epicentre, Madison, WI, USA) were run simultaneously on the gel.

\section{Computer analysis}

Transcription factor binding sites were predicted using Genomatix software (Munich, Germany); the MatInspector program, which uses TRANSFAC matrices; and the WebGene HCtata program's Hamming clustering method for TATA signal prediction in eukaryotic genes.

\section{Cloning and analysis of the human Jab1 promoter}

To clone the 5'-flanking region of the human Jab1 gene, a bacterial artificial chromosome clone containing the region corresponding to Jab1 was used as a template for PCR. The amplified DNA fragments were subcloned into the luciferase reporter vector pGL3 (Promega, Madison, W, USA). Progressive deletion mutants of the pGL3-Jab1 promoter were created by PCR. The integrity of constructs was confirmed by DNA sequencing. The following primers were used: $+83 \mathrm{R},-2006 \mathrm{~F},-2958 \mathrm{~F}$, $-946 \mathrm{~F},-658 \mathrm{~F},-472 \mathrm{~F},-344 \mathrm{~F},-127 \mathrm{~F}$, and -59F (Table 1).

\section{PCR and RT-PCR}

The PCR reaction contained $100 \mathrm{ng}$ of DNA template, $1.5 \mathrm{mM} \mathrm{MgCl}_{2}, 0.2 \mathrm{mM}$ dNTP (Roche Applied Science, Indianapolis, IN, USA), 1 uM of primers, and Taq High Fidelity DNA polymerase (Invitrogen, Carlsbad, CA, USA).

The reverse transcriptase (RT) assay was performed from $2 \mu \mathrm{g}$ of total RNA using Superscript II RT (Invitrogen, Carlsbad, CA, USA) according to the manufacturer's procedure. A reaction without RT was performed in parallel to ensure the absence of genomic DNA contamination. PCR amplification was carried out as described previously [22]. Conditions for the PCR reaction consisted of an initial denaturation step at $94^{\circ} \mathrm{C}$ for
5 minutes, followed by 30 cycles of 30 seconds at $94^{\circ} \mathrm{C}$, 30 seconds at $60^{\circ} \mathrm{C}$, and 30 seconds at $68^{\circ} \mathrm{C}$. After a final extension at $72^{\circ} \mathrm{C}$ for 10 minutes, PCR products were resolved on $1.2 \%$ agarose gels and visualized by ethidium bromide transillumination under UV light. Primers used were: Jab1 F296-314, Jab1 R1094-1076, Jab1 R883-864, GAPDH F, and GAPDH R. For these and all following primer sequences please refer to Table 1 .

\section{Transient transfection with reporter constructs and luciferase assay}

MCF7, MDA-MB-231, and MDA-MB-468 cells were plated into 24-well tissue culture dishes at $4 \times 10^{4}$ cells/ well 24 hours before transfection. Transfections were performed in triplicate according to the manufacturer's protocol using Lipofectamine PLUS reagent (Invitrogen, Carlsbad, CA, USA). Briefly, $0.4 \mu \mathrm{g}$ reporter plasmid Jab1-Luc (Firefly luciferase) together with $10 \mathrm{ng}$ of pRL (Renilla luciferase) were cotransfected. Luciferase assays were performed 36 hours after transfection using a Dual-Luciferase Reporter Assay System (Promega, Madison, W, USA). Firefly and Renilla luciferase activities were read on a Monolight 3010 luminometer (BD Bioscience, Rockville, MD, USA). Firefly luciferase activity was normalized to Renilla luciferase readings in each well. Each experiment was conducted at least twice in triplicate.

\section{Mutagenesis of the Jab1 promoter}

Site-directed mutagenesis of CEBP and GATA1 was performed according to the QuickChange II method (Stratagene, La Jolla, CA, USA). The following mutagenic primers were used: CEBP-Mut, GATA1-Mut, and GATA1-Del (see Table 1 for sequences). All mutants were verified by sequencing.

\section{Nuclear extract preparation and electrophoretic mobility shift assay}

Nuclear extracts were prepared as previously described [1]. Briefly, MCF7 and MDA-MB-468 cells were lysed in $10 \mathrm{mM}$ HEPES-KOH (pH 7.9), $10 \mathrm{mM} \mathrm{KCl,} 0.1 \mathrm{mM}$ EDTA, $0.1 \mathrm{mM}$ EGTA, $1 \mathrm{mM}$ DTT, and protease inhibitor cocktail (Roche Applied Science, Indianapolis, IN, USA). After incubation for 10 minute on ice, nuclei were recovered by centrifugation at $3,000 \times g$ at $4{ }^{\circ} \mathrm{C}$ for one minute and resuspended in $20 \mathrm{mM}$ HEPES-KOH (pH 7.9), 0.4 M NaCl, $1 \mathrm{mM}$ EDTA, 1 mM EGTA, 1 $\mathrm{mM}$ DTT, and protease inhibitor cocktail. Protein concentrations were determined using the DC Protein Assay (Bio-Rad Laboratories, Hercules, CA, USA). The following double-stranded DNA oligonucleotides were used in the electrophoretic mobility shift assays (EMSAs): -462/-436 CEBP-WT, -462/-436 CEBP-M1, 
Table 1 Sequences of oligonucleotides used in RT-PCR, primer extension, cloning site- directed mutagenesis, EMSA and ChIP

\begin{tabular}{|c|c|c|}
\hline Oligonucleotide & Sequence $\left(5^{\prime}\right.$ à $\left.3^{\prime}\right)$ & Purpose \\
\hline Jab1 F296-314 & ATCTCAGCATTGGCTCTGC & RT-PCR \\
\hline Jab1 R1094-1076 & TAACCTGAGACATCAATC & RT-PCR \\
\hline Jab1 R883-864 & AGAACTCAACGTATTCACCC & RT-PCR \\
\hline GAPDH F & CCACCCATGGCAAATTCCATGGCA & RT-PCR \\
\hline GAPDH R & TCTAGACGGCAGGTCAGGTCCACC & RT-PCR \\
\hline P1 & CGCTCCCGGACGCCGCC & Primer extension \\
\hline$+83 R$ & CTGAAAGCTTCGCTCCCGGACGCCGCC & Cloning \\
\hline$-2006 F$ & CTGACTCGAGGTGGTAGTGAGAGG & Cloning \\
\hline$-2958 F$ & CTGACTCGAGCGCATGGGAACCAA & Cloning \\
\hline$-946 F$ & TGAACTCGAGCCTGCTCCCTGTGTC & Cloning \\
\hline$-658 \mathrm{~F}$ & CTGACTCGAGCCCACTGCCTCCTCG & Cloning \\
\hline$-472 F$ & CTGAGCTAGCCAACAGACAGCCTT & Cloning \\
\hline$-344 F$ & CTGACTCGAGGAGGCCGAGCCTGC & Cloning \\
\hline$-127 F$ & TGAGCTAGCGTCCCGGAAAGGTCCCC & Cloning \\
\hline$-59 F$ & TGACTCGAGCTGCCCCAAGAGTC & Cloning \\
\hline$-31 F$ & CTGAGCTAGCGTTCCCGTGGTGCGG & Cloning \\
\hline CEBP-Mut & GCCTTACCTITTAGTCTITCctgAAACTTATCTC & Site-directed mutagenesis \\
\hline GATA1-Mut & CAACAAACTTgagTCATTTAAGGTACCTATACCC & Site-directed mutagenesis \\
\hline GATA1-Del & GTCTTTCAACAAACTT....CATTTAAGGTACC & Site-directed mutagenesis \\
\hline$-462 /-445$ CEBP WT & CCTTACCTTITAGTCTTTCAACAAACT & EMSA \\
\hline$-462 /-445$ CEBP Mut & CCTTACCTITAATCTTTCctgCAAACT & EMSA \\
\hline$-444 /-417$ GATA1 WT & AATCATTTATCTCATTTAAGGTACC & EMSA \\
\hline$-444 /-417$ GATA1 M1 & GGAGTCATTTAAGGTACCTATACCC & EMSA \\
\hline$-472 F$ & CTGACTCGAGCAACAGACAGC & ChIP \\
\hline$-343 R$ & CTGAAAGCTTCGCAGGCT & ChIP \\
\hline
\end{tabular}

Lower-case letters represent mutated oligonucleotides.

ChIP, chromatin immunoprecipitation; Del, deletion; EMSA, electrophoretic mobility shift assay; F, forward; Mut, mutant; M1, mutant-1; P, primer; R, reverse; RT$P C R$, reverse-transcription polymerase chain reaction; WT, wild-type.

-435/-417 GATA1-WT, and -435/-417 GATA1-M1 (see Table 1 for sequences).

Oligonucleotides were end-labeled with $\left[\gamma_{-}{ }^{32} \mathrm{P}\right]$ ATP (MP Biomedicals, Solon, OH, USA) by T4 polynucleotide kinase (New England Biolabs, Ipswich, MA, USA) and purified with Quick Spin G-50 Columns (Roche Applied Science, Indianapolis, IN, USA). Pre-binding of $5 \mu \mathrm{g}$ of nuclear extract to $0.05 \mathrm{mg} / \mathrm{mL}$ poly $(\mathrm{dI}: \mathrm{dC})$ (Roche, Applied Science, Indianapolis, IN, USA) was performed in a buffer containing $20 \mathrm{mM}$ HEPES $(\mathrm{pH}$ 7.4), $0.1 \mathrm{mM}$ EDTA (pH 8.0), $75 \mathrm{mM} \mathrm{KCl,} 2.5 \mathrm{mM}$ $\mathrm{MgCl}_{2}, 1 \mathrm{mM} \mathrm{DTT}$, and 5\% glycerol for 20 minutes at room temperature $\left(22\right.$ to $24^{\circ} \mathrm{C}$ ) before addition of 60,000 c.p.m. of labeled probe. For competition assays, 25- and 100-fold excess cold competitor oligonucleotide duplex was added to the reaction buffer 10 minutes before addition of the labeled probes. For supershift assays, antibodies were added for 20 minutes at $4^{\circ} \mathrm{C}$ prior to addition of the labeled probe. Reactions were resolved by electrophoresis on a $4.5 \%$ nondenaturing polyacrylamide gel run in $0.5 \times \mathrm{TBE}$, vacuum-dried with heat, and exposed to film at $-80^{\circ} \mathrm{C}$.

\section{Chromatin immunoprecipitation (ChIP) assay}

The manufacturer's protocol for the chromatin immunoprecipitation (ChIP) Assay Kit (Upstate Biotechnology, Temecula, CA, USA) was followed. Briefly, MCF7 cells or MDA-MB-231 cells transfected with control pcDNA vector or C/EBP- $\beta 2$ and were incubated with $1 \%$ formaldehyde for 20 minutes at $37^{\circ} \mathrm{C}$. Cells were collected, lysed, sonicated, and incubated with $4 \mu \mathrm{g}$ of antibodies to C/EBP- $\alpha$, C/EBP- $\beta$, GATA-1, Stat3, or $\beta$-actin overnight. PCR was used to amplify DNA bound to the immunoprecipitated histones after reversing the histoneDNA cross-links. The following primers were used for PCR: $-472 \mathrm{~F}$ and $-344 \mathrm{R}$ (see Table 1 for sequences).

\section{Transfection of small interfering RNA oligonucleotides}

Small interfering RNA (siRNA) for Stat3, Src, and Control (LUC) were obtained from Dharmacon (Lafayette, CO, USA). Oligonucleotides were transfected using Oligofectamine (Invitrogen, Carlsbad, CA, USA) following the manufacturer's protocol. For luciferase assay experiments, MDA-MB-468 cells were plated at $4 \times 10^{4}$ cells per well in a 24-well tissue culture dish. siRNA (20 
$\mathrm{nmol}$ and $50 \mathrm{nmol}$ ) were transfected in complete medium without antibiotics. The -472 Jab1-Luc construct and pRL were cotransfected 24 hours later using the manufacturer's protocol for Lipofectamine PLUS transfection reagent. Luciferase assays were performed after 48 hours.

\section{Results}

\section{Mapping the transcription initiation start site of the human Jab1 gene}

To determine the transcription start site of the Jab1 gene, primer extension analysis was performed. An antisense oligonucleotide ( $\mathrm{P} 1$ primer) was synthesized corresponding to the sequence located at the ATG translational start site according to the published sequence [GenBank accession no. NT008183]. The P1 primer was radio-labeled and extended using avian myeloblastosis virus reverse transcriptase and analyzed on a polyacrylamide-urea gel along with a DNA cycle sequencing reaction using the same primer. The primer extension experiment revealed an extension product of 71 nucleotides using the P1 primer (Figure 1a). The nucleotide 71 bp upstream of the ATG translation start site was designated the +1 transcription initiation site in the numbering of the nucleotide sequence throughout this study.

\section{Identification of the transcription elements located in the Jab1 promoter}

Based on the determined location of the transcription start site, we analyzed the Jab1 5' flanking region for a functional promoter. Using the MatInspector program, which uses TRANSFAC transcription factor binding site matrices, we identified a number of putative transcription factor binding sites upstream of the $J a b 1$ transcription start site (Figure 1b). A typical TATA box [23] was found $40 \mathrm{bp}$ upstream of the transcription start site, along with a CAAT box at $-99 \mathrm{bp}$. A number of putative transcription factor-binding elements were present in the promoter sequence, including STAT, ELK, p53, E2F, C/EBP, GATA, c-Myb, and AP-1.

\section{Identification of Cis-Acting elements within the Jab1 gene promoter}

To analyze the mechanisms responsible for transcriptional regulation of $J a b 1$, luciferase constructs were generated to evaluate $J a b 1$ promoter activity. A fragment of the human Jab1 promoter region from -2958 to +68 was amplified, sequenced, and subcloned into the luciferase reporter vector pGL3. To identify regulatory sequences that are important for transcriptional control of the Jab1 gene, we created a series of 5'-deletion constructs of the full length $J a b 1$ promoter and analyzed for their ability to drive the expression of luciferase in

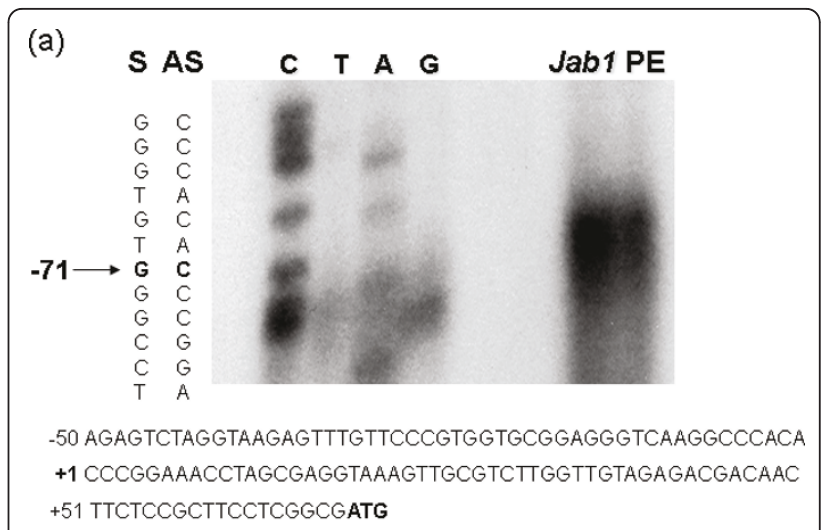

(b)

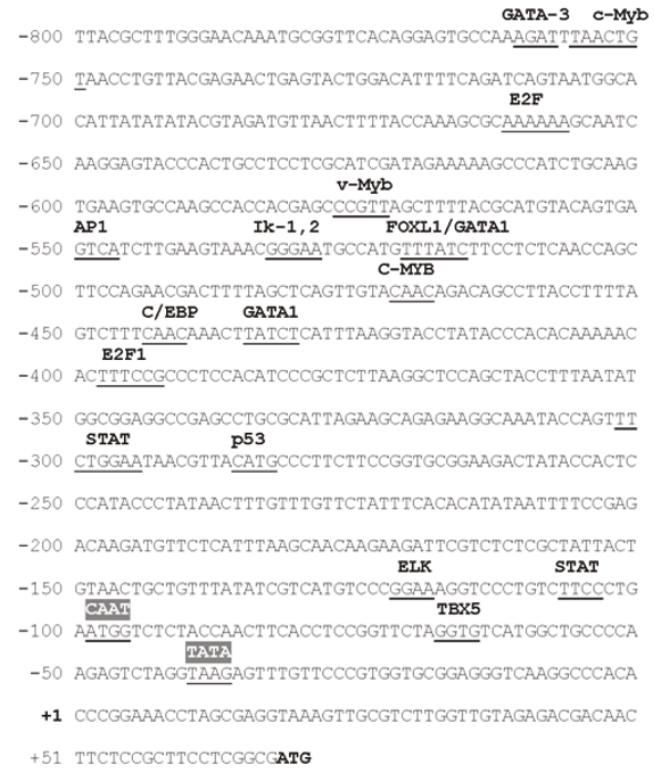

Figure 1 Identification of the transcriptional start site and promoter region of the human Jab1 gene. (a) Primer extension $(\mathrm{PE})$ analysis was performed using an oligonucleotide corresponding to the antisense sequence at the translational start site $(+1)$. A sequencing reaction using the same primer labeled with $\left[\gamma-{ }^{32} \mathrm{P}\right]$ ATP was included as a size marker and is shown on the left. An extension product of $71 \mathrm{bp}$ was observed. (b) Sequence of the promoter region of Jab1, with potential regulatory elements (underlined) identified according to the TRANSFAC databases. bp, base pairs; Jab1, c-Jun activation domain-binding protein-1.

MCF7 breast cancer cells (Figure 2a). Serial 5'-deletion mutations of the full-length promoter revealed a pattern of functional activity in transfected cells. The results suggest that the core promoter elements that drive maximal promoter activity are within the sequence spanning -472 and -345 upstream of the transcription initiation site, as the -344 Jab1-Luc construct displayed a marked loss of promoter activity (Figure 2a). Similar patterns of activity were seen in other breast cancer cell lines including BT-549, MDA-MB-231, SKBR3, and BT-474 (data not shown). Additionally, we evaluated the promoter strength in mammary tumor cells versus non-tumor 
(a)

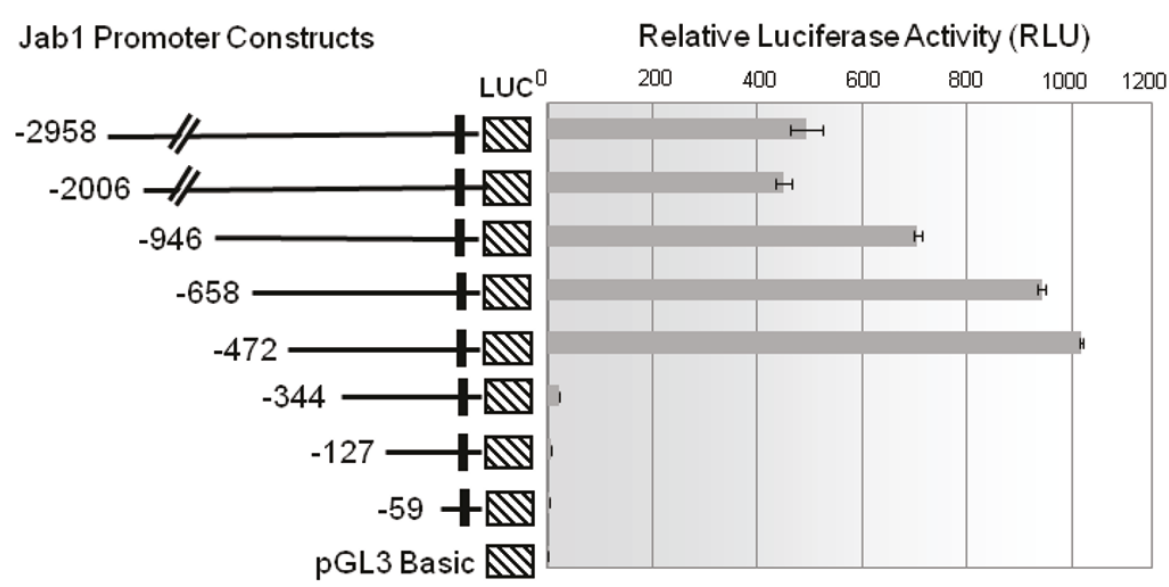

(b)

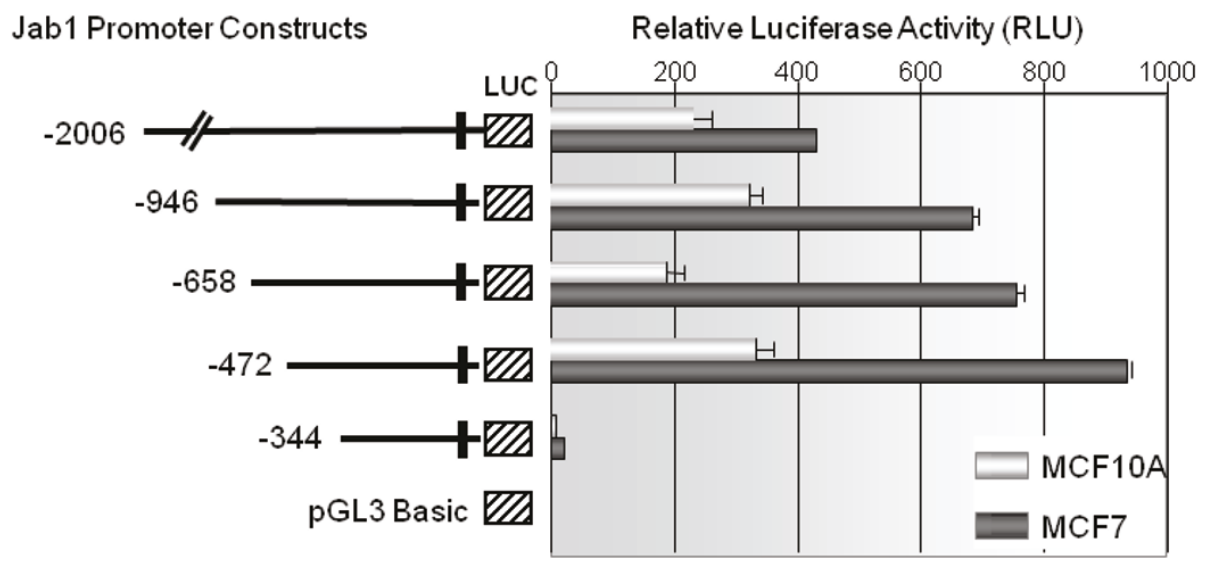

(c)

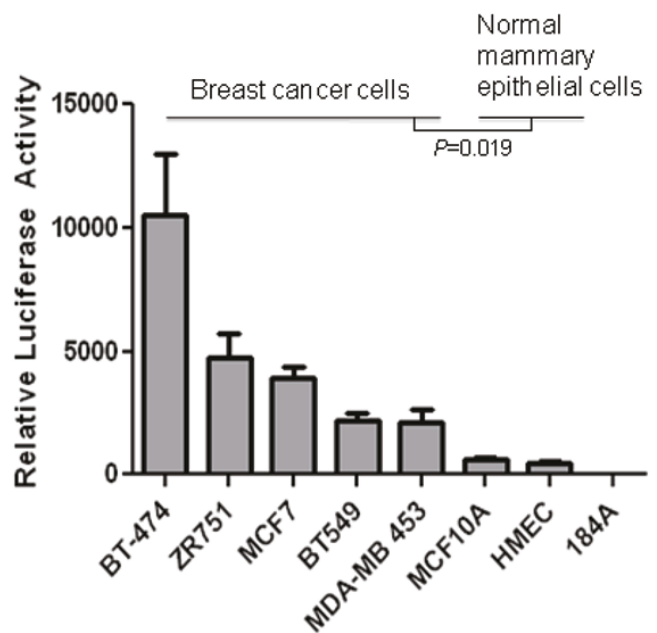

(d)

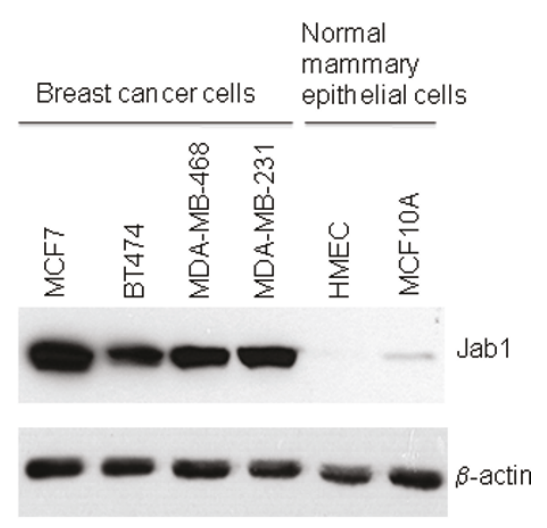

Figure $25^{\prime}$ deletion of the Jab1 promoter analysis reveals increased activity in breast cancer cells compared with normal cells. (a) Identification of the minimal promoter region of Jabl using progressive deletion of the $5^{\prime}$ region in luciferase reporter constructs. The plasmids were cotransfected with Renilla luciferase plasmid pRL-null (transfection control) into MCF7 cells, and luciferase activity was assayed. Values represent mean \pm standard error of triplicate experiments. Luciferase assays shown in subsequent figures were performed similarly. (b) Jab1 promoter $5^{\prime}$ deletion constructs were transfected into MCF7 and MCF-10A cells and subjected to luciferase reporter assays. Promoter activity was higher in MCF7 epithelial breast cancer cells than in non-tumorigenic epithelial MCF-10A cells. Deletion of the region -472 to -344 resulted in a loss of promoter activity in both cell lines. (c) A panel of breast cancer cells and normal mammary cells were transfected with the -472 Jab1-Luc construct. Significance is noted as ${ }^{*} P<0.05$ and ${ }^{*} P<0.01$ and was determined by t-test. (d) Jab1 protein levels for the cell lines in (c) were detected by western blotting, $\beta$-actin is shown as a control. Jab1, c-Jun activation domain-binding protein-1. 
cells. Jab1 promoter activity was three times higher in MCF7 breast cancer cells when observing the -472 construct than in MCF-10A normal mammary epithelial cells (Figure 2b). Further analysis of a panel of breast cancer cell lines including BT-474, ZR-75-1, MCF7, BT549, and MDA-MB-453 revealed higher Jab1 promoter activity compared to normal mammary epithelial cells MCF-10A, HMEC and 184A (Figure 2c). Jab1 protein levels were also found to be higher in the panel of breast cancer cells compared with the normal mammary epithelial cells HMEC and MCF-10A (Figure 2d). Therefore, the transcription factors responsible for promoting Jab1 transcription are either not present in normal cells or not as active as in tumor cells. Another possibility is that normal cells may express transcription suppressors acting on this region. In Figure $2 b$, the activity of the deletion constructs demonstrated differing ratios of luciferase activity between MCF7 and MCF-10A suggesting that different dominant regulatory factors may exist in each of these cell lines. However, interestingly, the same differential in promoter activity was seen between the -472 and -344 constructs in both cell lines.

\section{Identification of C/EBP and GATA transcription elements located in the $-472 /-345$ region of the Jab1 promoter}

Our data suggest that the -472 to $-345(-472 /-345)$ region is key to driving the transcription of Jab1. We therefore sought to identify the transcription factors that regulated $J a b 1$ through this region. Using the TRANSFAC database, we identified a number of putative transcription factor binding sites in the $-472 /-345$ region, including sites for C/EBP (-444/CAAC/-441) and GATA-1 (-435/TATCT/-431) (Figure 1b). Because these transcription factors are activated in some cases of tumorigenesis $[24,25]$, we speculated that they contributed to the increased transcription of Jab1.

$\mathrm{C} / \mathrm{EBPs}$ are a family of basic leucine-zipper transcription factors, including C/EBP- $\alpha, \mathrm{C} / \mathrm{EBP}-\beta,-\partial,-\varepsilon,-\gamma$, and $-\zeta[26]$. Of these, $C / E B P-\alpha,-\beta$, and $-\partial$ are expressed in the mammary gland, with $C / E B P-\beta$ proposed to play a role in breast cancer $[27,28]$. The GATA family of transcription factors is required for erythroid and megakaryocytic differentiation [29]. Unlike other GATA members, GATA-1 has not been associated with any solid tumors, but mutations in GATA-1 are associated with essentially all cases of acute megakaryoblastic leukemia in children with Down syndrome [30].

To pinpoint the functional significance of the C/EBP and GATA-1 binding sites detailed within the Jab1 promoter we performed promoter and EMSA analysis of these regions. Cloning of this region in front of the $-105 /+83$ sequence containing the TATA and CAAT boxes was sufficient to drive $J a b 1$ promoter activity (Figure 3a). To determine whether these putative elements are capable of binding transcription factors, we performed a series of EMSA experiments with nuclear extracts from MCF7 breast cancer cells. The oligonucleotides and mutants for the C/EBP and GATA-1 binding sites are shown in Figure $3 \mathrm{~b}$. The $-462 / 436$ and $-435 /-417$ probes showed transcription factor binding activity to the DNA containing the C/EBP and GATA-1 binding sites, respectively (Figure 3c). The cold specific oligonucleotides competed efficiently for binding, whereas a cold mutant competitor containing a mutation in the C/EBP or GATA-1 binding site did not. Further, a supershift was observed when the oligonucleotides were incubated with antibodies to C/EBP- $\beta$ and GATA-1 (Figure 3c).

To assess whether any of these sites is important for expression of Jab1, each was mutated individually in luciferase reporter plasmids. We introduced mutations in the $-472 /-345$ region of the Jab1 promoter to disrupt $\mathrm{C} / \mathrm{EBP}$ and GATA-1 binding and compared their activity with the -472 Jab1-Luc promoter construct in transient transfection assays. Mutation of either C/EBP or GATA-1 binding sequence reduced Jab1 promoter activity by approximately $40 \%$ and $20 \%$, respectively, and mutation of both sites resulted in a reduction of approximately $75 \%$ (Figure 3d). Interestingly, C/EBP and GATA binding sites homology from the human and mice promoter regions were found very well conserved [see Figure S1 in Additional file 1].

\section{C/EBP- $\alpha$, C/EBP- $\beta$, and GATA- 1 transactivate the Jab1 promoter}

Next, we examined which of the C/EBP and GATA family members are important for $J a b 1$ promoter activity. We cotransfected different members of the C/EBP and GATA family, C/EBP- $\alpha, \mathrm{C} / \mathrm{EBP}-\beta$, or $\mathrm{C} / \mathrm{EBP}-\delta$, or GATA1-6, into MCF7 cells, along with the -472 Jab1Luc plasmid (Figure 4a). Compared with control cells transfected with vector alone, cells transfected with $\mathrm{C} /$ EBP- $\alpha$, C/EBP- $\beta$, or GATA- 1 showed the greatest increase in -472 Jab1-Luc reporter activity (2.2-, 3.0-, and 2.6-fold, respectively). GATA-2 and GATA-3 also showed a significant increase in activity but for the purpose of this study were not studied in detail.

Interestingly, the transcription factor $C / E B P-\beta$ has been associated with breast cancer $[27,31]$. It is translated into three different isoforms: C/EBP- $\beta 1$, a $55-\mathrm{kDa}$ liver-enriched activating protein (LAP1); C/EBP- $\beta 2$, a 42- to 46-kDa protein also called LAP2 and; C/EBP- $\beta 3$ a $20-\mathrm{kDa}$ liver-enriched inhibitory protein (LIP) [25,32]. Of the three C/EBP- $\beta$ isoforms, LAP2 has been specifically observed in breast cancer, and overexpression of this isoform can induce epithelial-mesenchymal transition [28]. LIP, however, is unable to activate gene transcription, but is still able to bind to DNA and dimerize, 
(a)

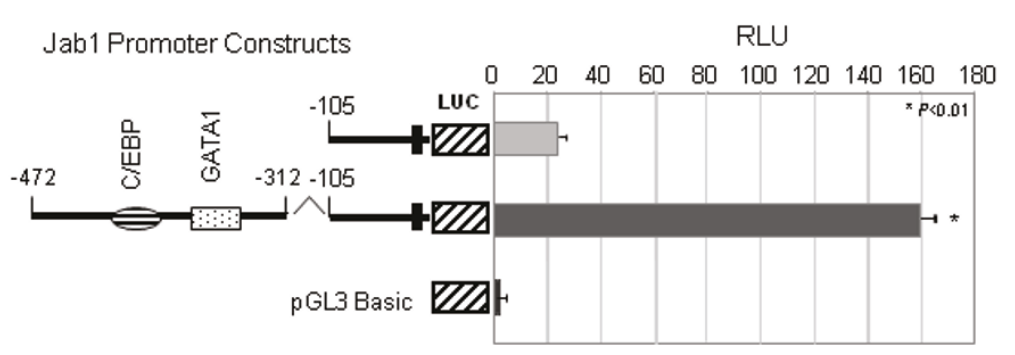

(b)

\begin{tabular}{|l|c|c|}
\hline EMSA Probes & Regions & Sequences $\left(5^{\prime} \rightarrow 3^{\prime}\right)$ \\
\hline C.EBP WT & -440 to $-414 \mathrm{bp}$ & CCTTACCTTTT AGTCT TTCAACAAACT \\
\hline C.EBP Mut. & -440 to $-414 \mathrm{bp}$ & CCTTACCTTTT AGTCT TTCCtgAAACT \\
\hline GATAWT & -412 to $-389 \mathrm{bp}$ & AATCATTATCTCATTT AAGGTACC \\
\hline GATAMut & -412 to $-389 \mathrm{bp}$ & AATCAT ggagTCATT TAAGGTACC \\
\hline
\end{tabular}

(c) Cold Competitors:

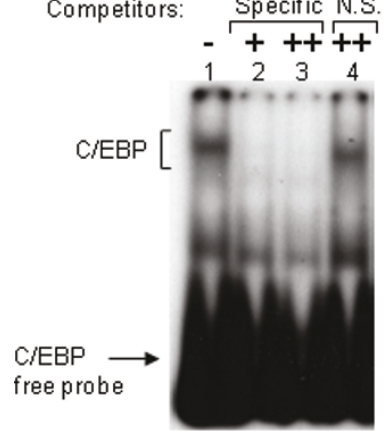

Cold

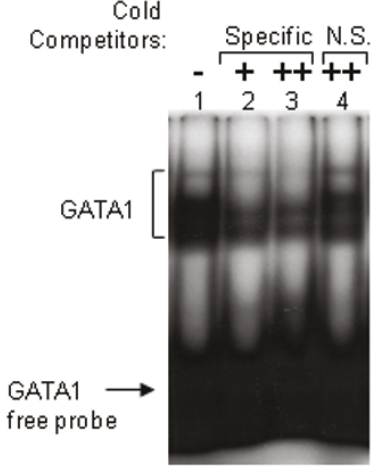

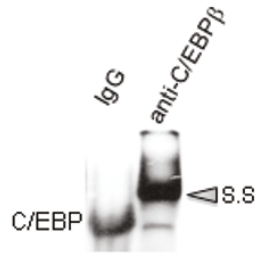

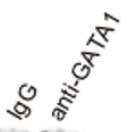

GATA1

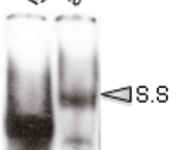

(d)

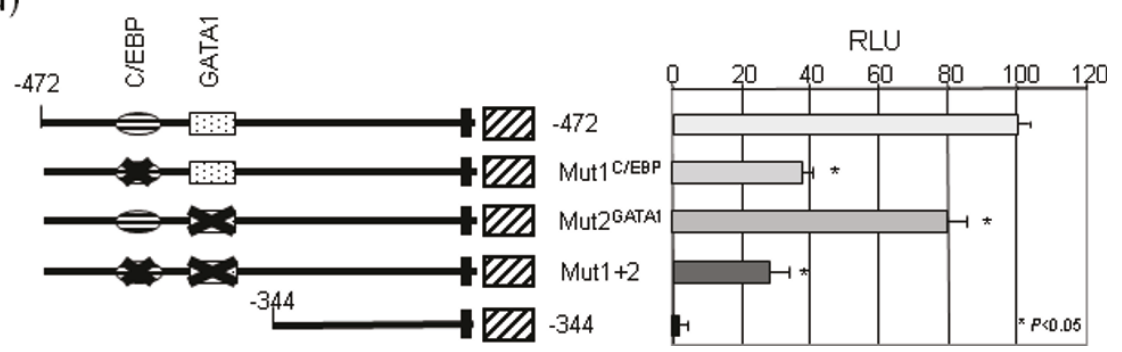

Figure 3 Functional analysis of the Jab1 promoter. (a) The -472/-312 region contains a regulatory sequence that is sufficient to activate transcription of the Jab1 promoter when cloned in front of the TATA and CAAT boxes. MCF7 cells were transfected with either the -105/+83Luc or $-472 /-312$, and -105/+83 Jab1-Luc constructs and subjected to luciferase reporter assays. Values were compared with the -105 Jab1-Luc reporter by Student's t test, ${ }^{*} P<0.01$. (b) Sequence of the probes used in EMSA assays. The probes span the sequence from -440 to -414 or from -412 to -389 of the Jab1 promoter and encompass the C/EBP or GATA sites. (c) Binding of C/EBP and GATA-1 to the Jab1 promoter. EMSAs showing binding of nuclear proteins C/EBP and GATA-1 to the C/EBP and GATA-1 binding sites of the Jab1 promoter. End-labeled oligonucleotide probes corresponding to the -440/-414 (C/EBP) or -413/-389 (GATA-1) regions of the WT Jab1 promoter sequence were incubated with nuclear extract proteins from MCF7 cells and separated on a 4.5\% polyacrylamide gel. Lane 1 shows binding between probe and nuclear extract. Specificity was determined by addition of 50 and 100 molar excess of unlabeled specific cold probe, and mutant probe as specific and nonspecific (NS) competitors as indicated. Lane 4 shows complexes observed in the presence of probes containing mutations in C/ EBP or GATA-1. Supershift of the complex was observed following incubation with C/EBP $\beta$ or GATA-1 antibodies as shown in the right panels. (d) MCF7 cells were transfected with the -472 Jab1-Luc, -472 C/EBP mutant (Mut1 C/EBP), -472 GATA-1 mutant (Mut $2^{\text {GATA1 }}$ ), Mut1+2, or -344 Jab1-Luc plasmids. Mutation of the C/EBP(Mut1 ${ }^{\text {CEBP }}$ ) and GATA-1 (Mut2 ${ }^{\text {GATA1}}$ ) binding sites reduced Jab1 promoter activity by about $60 \%$ and $20 \%$, respectively, and by $75 \%$ when mutated together. The firefly luciferase activity of each sample was normalized to that of Renilla luciferase (pRL). Data present the mean \pm standard deviation of three independent experiments. All values were compared with the -472 Jab1-Luc reporter by Student's $t$ test. C/EBP, CCAAT/enhancing binding protein; EMSA, electrophoretic mobility shift assay; Jab1, c-Jun activation domain-binding protein-1; NS, nonspecific binding; SS, supershift. 
(a)

(b)
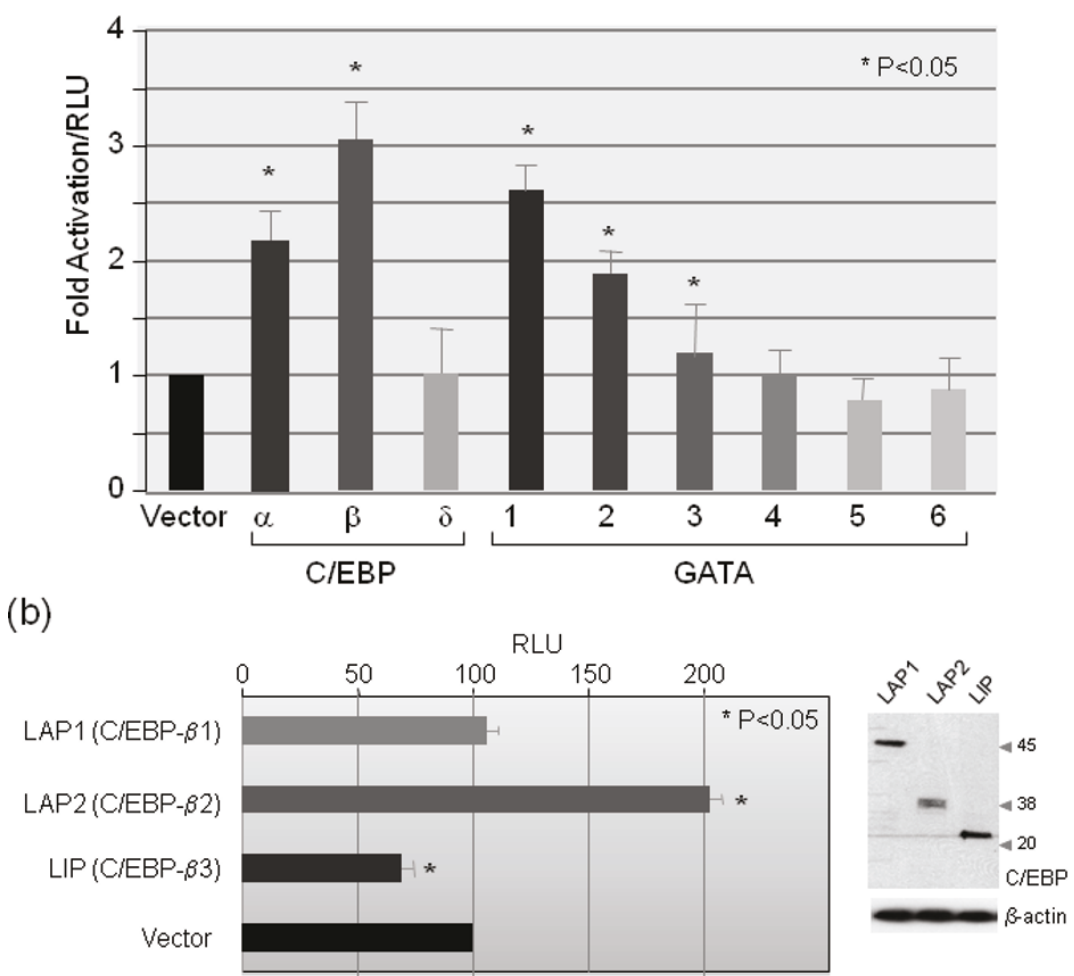

(c)

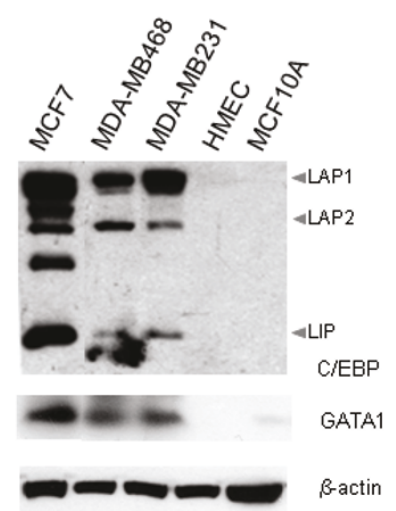

(d)
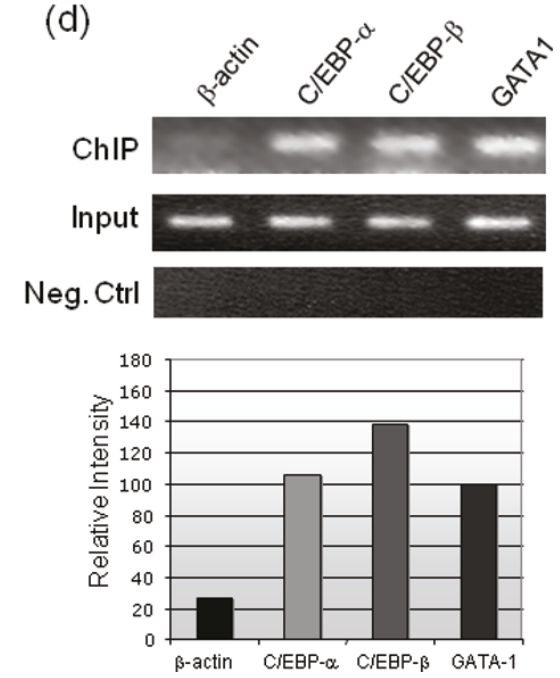

Figure 4 C/EBP- $\alpha$, C/EBP- $\beta$ and GATA-1 transactivate the Jab1 promoter. (a) -472/+83 Jab1-Luc reporter plasmid was cotransfected with expression plasmids for C/EBP- $\alpha, C / E B P-\beta, C / E B P-\delta$, and GATA-1-6. The results are presented as fold activation compared with cells transfected with pcDNA3.1 vector control. All values were compared with the vector control by Student's t test. (b) Left, LAP1 (C/EBP- $\beta$ 1), LAP2 (C/EBP- $\beta 2$ ), or LIP (C/EBP- $\beta 3$ ) plasmids, along with the -474 Jab1-Luc promoter construct, were cotransfected with the Renilla luciferase plasmid pRL-null (transfection control) into MCF7 cells, and luciferase activity was assayed. Right, western blot analyses to demonstrate the protein expression of LAP1, LAP2 and LIP. (c) Endogenous expression of the C/EBP $\beta$ isoforms (LAP1, LAP2, and LIP) and GATA-1 were detected at higher levels in breast cancer cell lines compared with normal mammary epithelial cells by western blot analysis. (d) Identification of proteins in complexes by ChIP assays. Antibodies to $\beta$-actin, C/EBP- $\alpha$, C/EBP- $\beta$, or GATA-1 were used to immunoprecipitate protein/DNA complexes from the sonicated lysates of MCF7 cells. After reversing the cross-linking, DNA was precipitated and PCR was performed using primers to amplify the $-472 /-344$ promoter DNA. As a negative control, primers for the upstream promoter region -642/-475 were used. Bottom panel represents quantification of the data with ImageJ software. C/EBP, CCAAT/enhancing binding protein; ChIP, chromatin immunoprecipitation; Jab1, c-Jun activation domainbinding protein-1; LAP, liver-enriched activating protein; LIP, liver-enriched inhibitory protein; PCR, polymerase chain reaction; pRL, Renilla luciferase reporter vector; RT-PCR, reverse transcription polymerase chain reaction. 
and therefore acts as a dominant negative [27]. It has been suggested that the LAP/LIP ratio may be an important indicator of C/EBP- $\beta$ transcription [25]. We found that LAP2 activates the Jab1 promoter (over twofold), whereas LAP1 had little effect and LIP decreased activity by about $16 \%$ (Figure $4 \mathrm{~b}$ ). Further, analysis of the C/EBP $\beta$ isoforms in breast cancer cells compared with normal, revealed higher levels of the LAP-1 and -2 isoforms in MCF7, MDA-MB-468 and MDA-MB-231 breast cancer cells compared with normal mammary epithelial cells HMEC and MCF-10A (Figure 4c). Interestingly, the LIP expression was also expressed at higher levels in the breast cancer cells compared with normal (Figure 4c). This in line with the increased endogenous Jab1 expression detected in these breast cancer cells compared with the normal mammary epithelial cells as shown in Figure 2d. We also detected higher GATA-1 expression in the breast cancer cells compared with normal mammary epithelial cells and taken together could be a driving force in leading Jab1 expression in breast cancer.

C/EBP- $\alpha$, C/EBP- $\beta$, and GATA- 1 bind to the Jab1 promoter To further determine whether C/EBP isoforms and GATA-1 bind to the Jab1 promoter, we performed ChIP assays on chromatin obtained from MCF7 cells (Figure $4 \mathrm{~d}$ ). When chromatin was incubated with $\beta$ actin, no product was observed. When chromatin was incubated with antibodies to $\mathrm{C} / \mathrm{EBP}-\alpha, \mathrm{C} / \mathrm{EBP}-\beta$, and GATA-1 and the $-472 /-344$ region was amplified by $\mathrm{PCR}$, a product was observed. These data suggest that C/EBP- $\alpha, C / E B P-\beta$, and GATA- 1 bind specifically to the $-472 /-344$ region of the Jab1 promoter.

\section{Stat3 enhances the activity of C/EBP- $\alpha$ and C/EBP- $\beta$ on the Jab1 promoter}

The C/EBP transcription factors form heterodimers with other $\mathrm{C} / \mathrm{EBP}$ family members and other transcription factors. We observed that Jab1-driven luciferase reporter activity increased upon addition of conditioned medium to MCF7 cells (data not shown). One of the pathways activated by conditioned medium is the Stat3 pathway, which has also been linked with breast tumorigenesis [33]. Moreover, Stat3 has been shown to interact with the C/EBP transcription factors and increase their activity [24]. We therefore investigated whether Stat3 can transactivate the $J a b 1$ promoter, alone or in combination with $\mathrm{C} / \mathrm{EBP}-\alpha$ or $\mathrm{C} / \mathrm{EBP}-\beta$. Stat 3 alone increased $J a b 1$ promoter activity, but Stat3 along with C/EBP- $\alpha$ and C/EBP- $\beta$ synergistically increased $J a b 1$ promoter activity (Figure $5 \mathrm{a}$ ), suggesting that Stat 3 interacts with $\mathrm{C} / \mathrm{EBP}$ on the Jab1 promoter. To that end, we observed a STAT general consensus site (TTN5AA) [34] that overlaps the C/EBP site within the Jab1 promoter sequence (-472 to -345$)$ and was not identified by transcription factor database searches (Figure 5b). Stat1, Stat3, Stat4, and Stat92E all bind to this generalized consensus site $[34,35]$.

We next performed a ChIP assay to determine whether Stat 3 could bind with C/EBP- $\beta 2$ co-operatively to the Jab1 promoter using MDA-MB-231 cells, which have constitutively activated Stat3. Since C/EBP- $\beta 2$ (or LAP2) seems to be a major activator of the Jab1 promoter (Figure 4), we next focused only on C/EBP- $\beta 2$. Binding of Stat3 to the Jab1 promoter was increased greater than seven-fold when $C / E B P-\beta 2$ was transfected into the cells (Figure $5 \mathrm{c}$ ). Taken together, these data suggest that C/EBP- $\beta 2$ and Stat 3 bind to the Jab1 promoter to increase Jab1 promoter activities.

We further investigated whether inhibition of Stat3 affects Jab1 promoter activity in MDA-MB-468 cells, which have constitutively activated Stat3. Expression of a dominant-negative mutant of Stat3 reduced over $80 \%$ Jab1 promoter activity (Figure $5 \mathrm{~d}$ ). The EEE/VV mutation renders the protein incapable of DNA binding [36]. Expression of exogenous wild type Stat3 increased Jab1 expression, whereas the dominant-negative EEE/VV mutation reduced Jab1 protein levels (Figure 5e).

\section{Inhibition of Stat3 and Src decrease Jab1 promoter activity and protein expression}

To further demonstrate the regulation of Jab1 by Stat3, we examined the effect of inhibition of Stat 3 and also its upstream activator Src using siRNA $[37,38]$. Inhibition of Stat3 and Src by siRNA resulted in a dramatic reduction of $J a b 1$ promoter activity (Figure 6a), mRNA levels (Figures 6b and 6c), and Jab1 protein expression (Figure 6d). Similar results were obtained with MDAMB-231 cells (data not shown). Collectively, these results demonstrate that the $\mathrm{Src} / \mathrm{Stat} 3$ signaling pathway plays an important role in the regulation of Jab1 transcription.

\section{Stat3-induced Jab1 transcriptional activation and protein expression}

To determine the biological significance of Stat3mediated Jab1 expression, the role of Stat3 in normal human breast epithelial cells was investigated. As Jab1 expression in normal mammary epithelial cells is low, we asked whether overexpression of Stat3 could enhance $J a b 1$ transcription in these cells. Ectopic expression of Stat3 in normal mammary epithelial cells (MCF-10A and MCF-10F) resulted in increased Jab1 mRNA and protein levels (Figures $7 \mathrm{a}$ and $7 \mathrm{~b}$ ). Therefore, the Stat3 transcription factor is in part responsible for promoting Jab1 transcription in breast cancer cells and is either not present or not as active in the MCF-10A and MCF$10 \mathrm{~F}$ cells. 


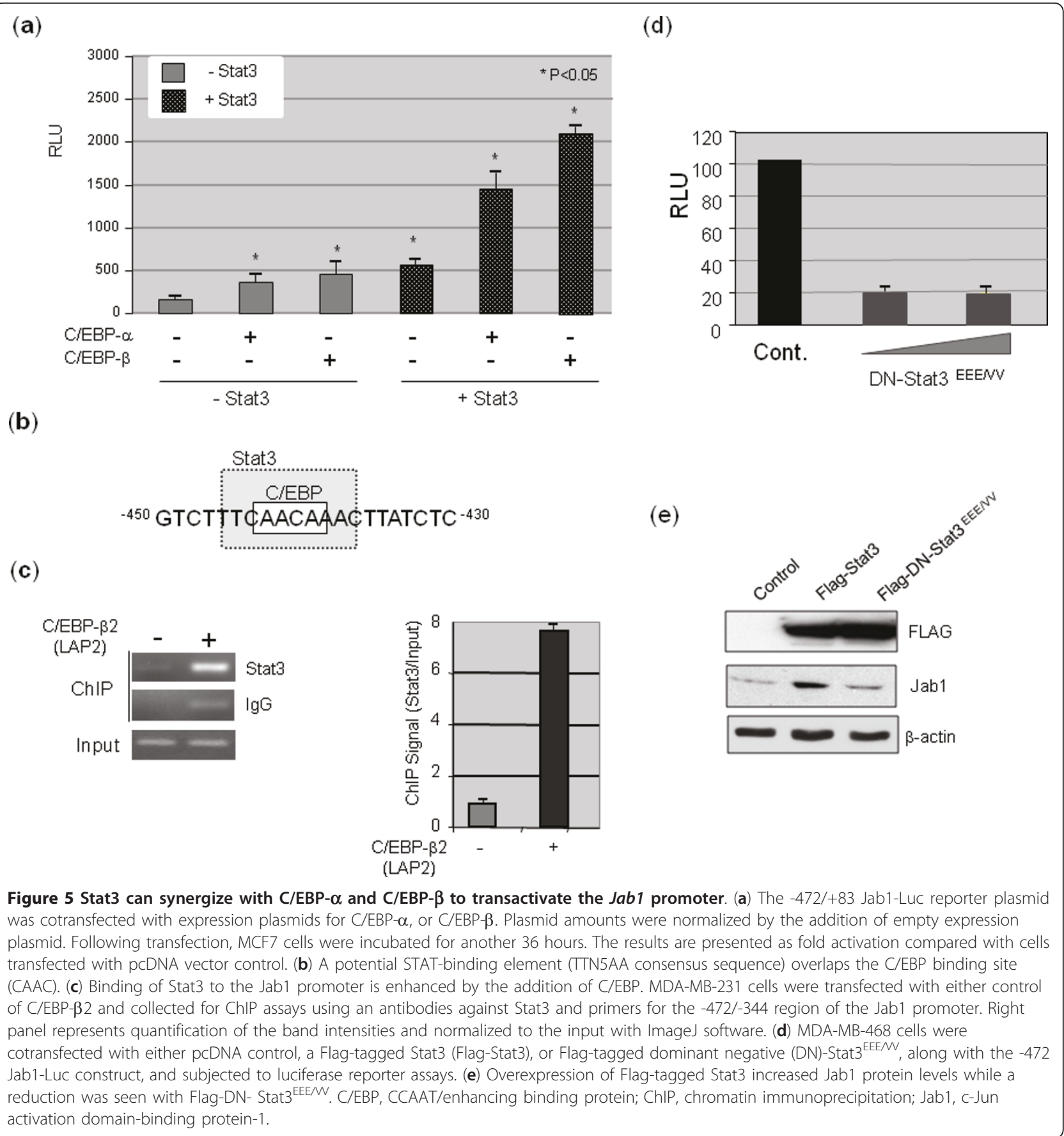

We further investigated whether an upstream activator of Stat3, the cytokine IL-6, could be driving increased Jab1 expression. Treatment with IL- 6 for 30 minutes increased phosphorylation of Stat 3 on tyrosine 705 and resulted in increased Jab1 mRNA (Figure 7c) and protein levels (Figure 7d) within the short time of $30 \mathrm{~min}$ utes, 1 hour, and 4 hours that was partially blocked by the addition of the Stat3 inhibitor Stattic. The same trends were observed in the breast cancer cell line T47D and the mammary epithelial cells, MCF-10A. IL-6 also resulted in increased Jab1 promoter activity in MCF7 and T47D cells [See Figure S2 in Additional file 1].

Taken together, it is evident that both IL-6 and Src signaling through Stat3 is contributing to Jab1 transcription and increased expression in breast cancer. Further, it is possible that Stat3 and C/EBP $\beta$ could be binding to the Jab1 promoter either separately or together to mediate increased $J a b 1$ transcriptional activity. A proposed 


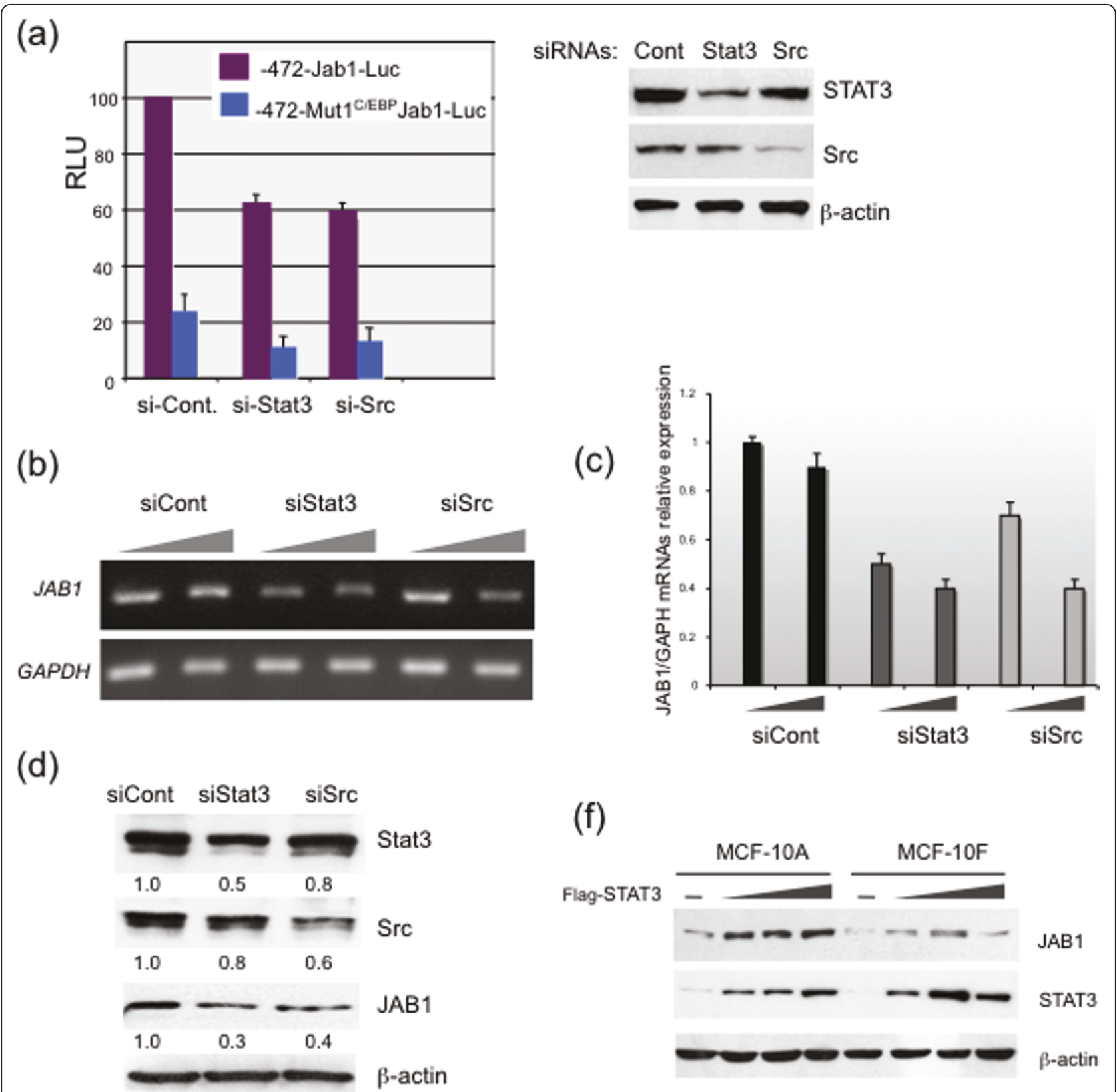

Figure 6 Inhibition of Stat3 and Src by siRNA reduces Jab1 promoter activity in breast carcinoma cells. (a) MDA-MB-468 cells were cotransfected with siRNA targeting Stat3 (siStat3) or SrC (siSrc), along with either the -472 Jab1-Luc construct or -472-Mut1 ${ }^{\text {C/EBP }}$ Jab1-Luc (as a control) and subjected to luciferase reporter assays, western blot analyses to demonstrate the efficient knockdown of Stat3 and Src protein levels are shown in the right panel. (b) MDA-MD-468 cells were transfected with increasing doses of siStat3 and siSrc and Jab1 was detected by RTPCR, quantification of Jab1 RNA levels is shown in (c). (d) Western blot analysis demonstrates that Jab1 protein levels decreased following inhibition of Stat3 and Src by siRNA. Jab1, c-Jun activation domain-binding protein-1; Mut, mutation; siRNA, small interfering RNA; RT-PCR, reverse transcription polymerase chain reaction; STAT, signal transducer and activator of transcription.

model for the activation of Jab1 transcription is shown in Figure 7e.

\section{Discussion}

Jab1 is commonly overexpressed in patients with breast cancer as well as other tumor types. The mechanism by which Jab1 is regulated is currently not known and our data suggest that this may occur at the transcriptional level. In this study, the Jab1 promoter was analyzed to identify the molecular basis of Jab1 gene expression and to give insight into the mechanisms by which Jab1 is overexpressed in cancer. Jab1 promoter analysis led to 


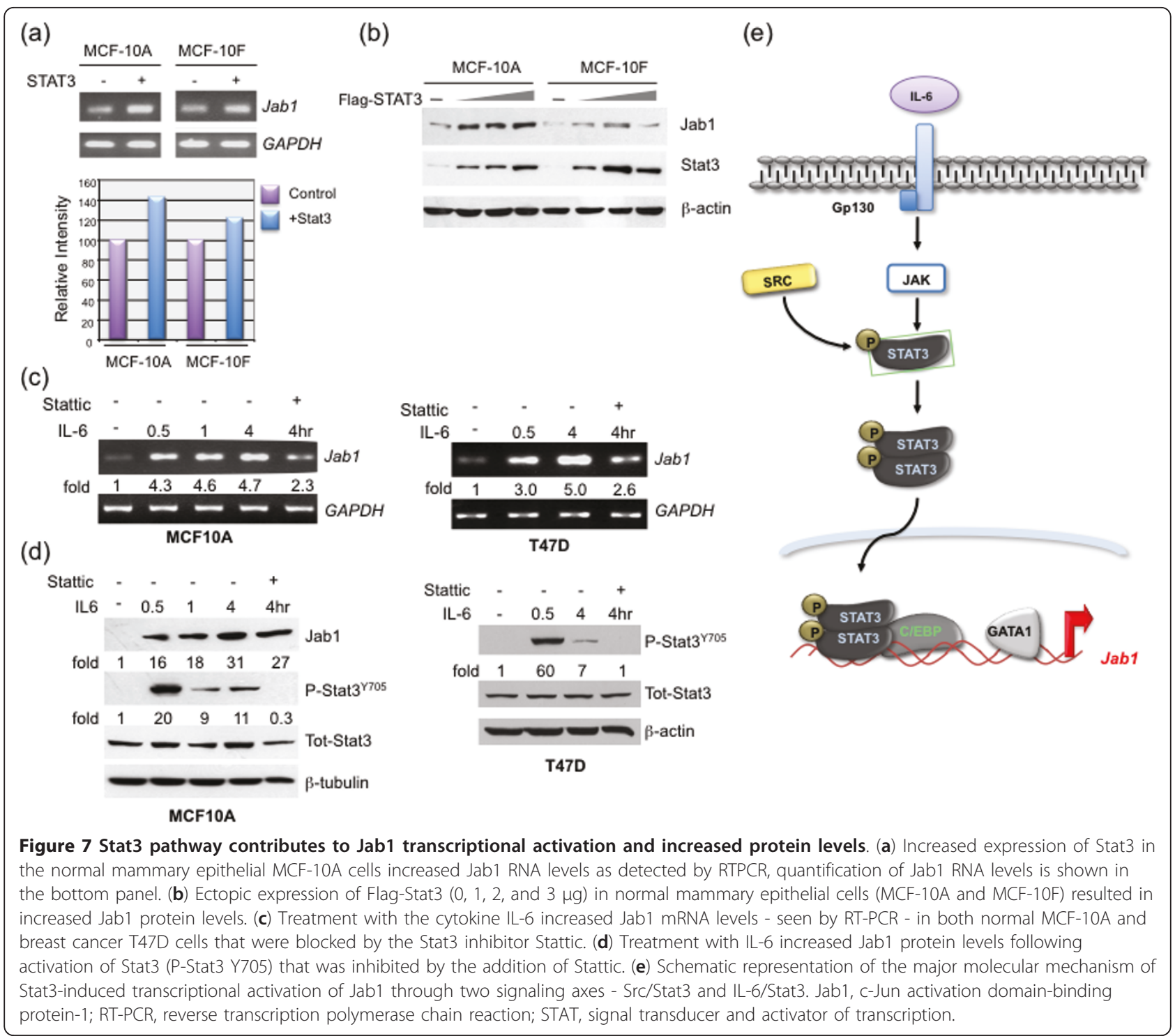

the identification of C/EBP- $\beta$, GATA-1, and Stat 3 as positive regulators of $J a b 1$ transcription in breast cancer cells. Promoter deletion studies identified a region between -472 and -345 that has significant transcriptional activity, as evidenced by the dramatic reduction in luciferase reporter activity when this region has been deleted (Figure 2a). Mutation of both the C/EBP and GATA-1 sites together resulted in decreased luciferase reporter activity of approximately $75 \%$ when combined. We identified C/EBP, GATA-1, and Stat3 consensus sequences located in this region and their binding was confirmed by EMSA and ChIP assays. We established that C/EBP, GATA-1, and Stat3 are positive regulators of $J a b 1$ promoter activity. As these transcription factors are activated during tumorigenesis, and because Jab1 is overexpressed in a number of tumors, we demonstrate that these transcription factors indeed increase transcription of Jab1.

In our study, we identified C/EBP as a potential transcriptional activator for $J a b 1$, specifically $\mathrm{C} / \mathrm{EBP} \alpha$ and $\mathrm{C} / \mathrm{EBP} \beta-2$. C/EBP $\beta-1$ is expressed in normal breast cells while expression of $\mathrm{C} / \mathrm{EBP} \beta-2$ is known to be expressed specifically in invasive primary breast tumor samples or cells lines [39]. Of the three isoforms of C/EBP- $\beta$, the transactivating form of LAP2 resulted in a two-fold increase in $J a b 1$ transcriptional activity while the inhibitor isoform LIP decreased activity. C/EBP- $\beta$ appears to play a critical role in the development of both the mammary gland and cancers therein through its involvement in development, differentiation, and proliferation of mammary epithelial cells $[25,27,31]$. As Jab1 is frequently upregulated in breast cancer, it is possible that 
LAP2 is a major factor in driving Jab1 transcription during the tumorigenic process. Of note, our study detected higher levels of all three C/EBP- $\beta$ isoforms in a panel of breast cancer cell lines compared with normal mammary epithelial cells (Figure 4d), which is contrary to previous studies that identified mainly higher expression of LAP2 in breast cancer. Yet, LAP2 was the isoform that resulted in the greatest increase in transcriptional activity of Jab1. This increased expression could certainly be driving increased Jab1 activity in breast cancer cells.

Further, we identified a co-existing Stat3 binding site within the C/EBP binding site on the Jab1 promoter. Ectopic overexpression of Stat 3 increased transcriptional activity as well as mRNA and protein levels of Jab1. This was further increased with overexpression of the activated form of Stat3. Constitutive activation of Stat3 occurs commonly in cancer, including breast cancer and has been demonstrated to contribute to tumorigenic processes [40]. Stat3 can mediate signaling through upstream receptor tyrosine kinases such as epidermal growth factor receptor (EGFR) and platelet-derived growth factor receptor (PDGR) as well as upstream non-receptor tyrosine kinases such as Abl and Srcrelated kinases. These receptors are constitutively activated in cancer, typically through genetic alterations [40]. The oncogenic Src protein kinase itself is overexpressed in a large number of tumor types and interacts with multiple tyrosine kinase receptors, including EGFR and HER2 [41] to mediate its oncogenic effects of promoting growth and metastasis. We found that Src, an activator of Stat3, is involved in Jab1 transcription. Overexpression of both Stat3 and Src in normal mammary epithelial cells resulted in increased Jab1 mRNA and protein levels. These data provide the first evidence that Jab1 is a direct downstream target of Stat3 and Src. Additionally, inhibition of Src by siRNA reduced Jab1 promoter activity in a manner similar to inhibition of Stat3. We further identified one upstream activator of Stat3, IL-6, that mediated activation of Jab1 expression.

Since the present study began, Jab1 expression has been linked to the HER2 signaling pathway. HER2 has been found to stimulate $J a b 1$ transcriptional activity in NIH3T3 cells stably expressing the HER2 receptor [21]. This stimulation took place through the AKT/ $\beta$-catenin/ TCF-4 signaling pathway in breast cancer cells overexpressing the HER2 receptor. The TCF binding site is in the same area as our region of interest, between -472 and -344. In our laboratory, we also found overexpression of Jab1 in NIH3T3 and MCF7 cells that stably express the HER2 receptor (data not shown). However, inhibition of this pathway by the anti-HER2 antibody trastuzumab (Herceptin) or AKT inhibitors in MCF7 and SKBR3 cells did not reduce Jab1 promoter activity.
However, trastuzumab did inhibit Jab1 protein levels in BT-474 breast cancer cells as well as phosphorylation of AKT and Stat3 (data not shown). The regulation of Jab1 expression by HER2 through the AKT pathway is of great interest, and further studies could strengthen our understanding on the role of Jab1 in the tumorigenic process.

As overexpression of Jab1 is frequently observed in breast cancer, further investigation of the pathways that modulate $J a b 1$ transcription would provide insight into the role Jab1 plays in the tumorigenic process therein. Activation of the Stat 3 pathway in breast cancer can occur through many pathways, including those of EGFR, HER2, IL-6 receptors, IL-11 receptors, and progesterone receptors [42]. Experimental activation of these pathways, followed by evaluation of $J a b 1$ promoter activity and mRNA levels, could provide insight into the mechanisms by which Jab1 transcription is activated. Our data provide evidence of activation of $J a b 1$ transcription through IL-6 and Src mediated activation of Stat3 as shown in Figure 7e. It is possible that other activators upstream of Stat 3 could be mediating this downstream effect as well and warrants further investigation.

\section{Conclusions}

In summary, the present study demonstrates that the $\mathrm{Src} / \mathrm{Stat} 3$ and C/EBP signaling pathways positively regulate the expression of the Jab1 oncogene. Our results show that Stat3 and LAP2 (C/EBP- $\beta 2)$ are the two major transcription factors that contribute to Jab1 overexpression that leads to increased proliferation of breast cancer cells. Our findings reveal a novel mechanism of Jab1 regulation and provide functional and mechanistic links between two major signaling axes - Src/Stat3 and IL-6/Stat3 - that are involved in controlling Jab1 oncogenic protein activation. Understanding the mechanisms by which Jab1 expression is deregulated may help in the development of drugs that target additional key elements responsible for this important deregulation.

\section{Additional material}

Additional file 1: Figure S1. C/EBP and GATA binding sites homology from the human and mice promoter regions.Figure S2. IL-6 mediated activation of Jab1 promoter activity.

\section{Abbreviations}

C/EBP: CCAAT/enhancing binding protein; ChIP: chromatin

immunoprecipitation; CRL: cullin-RING-ubiquitin ligase; CSN: COP9 signalosome; CUL-1: cullin 1; DMEM: Dulbecco's modified Eagle's medium; EGFR: epidermal growth factor receptor; EMSA: electrophoretic mobility shift assay; FBS: fetal bovine serum; Jab1: c-Jun activation domain-binding protein-1; JAMM: Jab1 MPN domain metalloenzyme; HER: human epidermal 
growth factor receptor; HIF-1a: hypoxia inducible factor-1 alpha; LAP: liverenriched activating protein; LIP: liver-enriched inhibitory protein; MIF: macrophage migration inhibitory factor; PCR: polymerase chain reaction; PDGR: platelet-derived growth factor receptor; RT-PCR: reverse-transcription polymerase chain reaction; siRNA: small interfering RNA; STAT: signal transducer and activator of transcription; TCF: T-cell transcription factor.

\section{Acknowledgements}

TJS is a recipient of fellowships from Susan G. Komen Foundation and the Department of Defense Breast Cancer Research Program; TTV is a recipient of fellowships from Vietnam Education Foundation. This study was supported by grants from the National Cancer Institute (RO1-CA90853) and the Susan G. Komen Breast Cancer Foundation to FXC. The authors thank Dr. Prahlad Ram for the Stat3 DNA constructs and Dr. Linda Sealy for the C/ EBPB 1-3 (LAP1, LAP2, and LIP) plasmids. They appreciate the technical assistance of Sarah May and editing assistance of Pierrette Lo.

\section{Author details}

'Department of Systems Biology, Unit 950, University of Texas - MD Anderson Cancer Center, 1515 Holcombe Boulevard, Houston, TX 77030, USA. ${ }^{2}$ Department of Experimental Therapeutics, University of Texas - MD Anderson Cancer Center, 1515 Holcombe Boulevard, Houston, TX 77030, USA.

\section{Authors' contributions}

TJS carried out all of the studies and drafted the manuscript. QZ assisted in many aspects of the study including the execution of deletion analysis and siRNA analysis. LT contributed to the cloning of Jab1 promoter and its analysis. VTT and AMB participated in cell culture, siRNA, and western blotting experiments. ALK provided plasmid constructs, assisted in the primer extension analysis and participated in study design. XFL and WSL, participated in the study design, and provided important intellectual support. FXC conceived the study, participated in its design, coordination and interpretation of the results and finalized the manuscript. All authors read and approved the final manuscript.

\section{Competing interests}

The authors declare that they have no competing interests.

Received: 8 October 2010 Revised: 21 March 2011

Accepted: 20 June 2011 Published: 20 June 2011

\section{References}

1. Claret FX, Hibi M, Dhut S, Toda T, Karin M: A new group of conserved coactivators that increase the specificity of AP-1 transcription factors. Nature 1996, 383:453-457.

2. Schwechheimer C, Deng XW: COP9 signalosome revisited: a novel mediator of protein degradation. Trends Cell Biol 2001, 11:420-426.

3. Chamovitz DA, Segal D: JAB1/CSN5 and the COP9 signalosome. A complex situation. EMBO Rep 2001, 2:96-101.

4. Shackleford TJ, Claret FX: JAB1/CSN5: a new player in cell cycle control and cancer. Cell Div 2010, 5:26.

5. Cope G, Suh GS, Aravind L, Schwarz SE, Zipursky SL, Koonin EV, Deshaies RJ: Role of predicted metalloprotease motif of Jab1/Csn5 in cleavage of Nedd8 from Cul1. Science 2002, 298:608-611.

6. Wei N, Serino G, Deng XW: The COP9 signalosome: more than a protease. Trends Biochem Sci 2008, 33:592-600.

7. Tomoda K, Kubota Y, Kato J: Degradation of the cyclin-dependent-kinase inhibitor p27Kip1 is instigated by Jab1. Nature 1999, 398:160-165.

8. Bech-Otschir D, Kraft R, Huang X, Henklein P, Kapelari B, Pollmann C, Dubiel W: COP9 signalosome-specific phosphorylation targets $\mathrm{p} 53$ to degradation by the ubiquitin system. Embo J 2001, 20:1630-1639.

9. Oh W, Lee EW, Sung YH, Yang MR, Ghim J, Lee HW, Song J: Jab1 induces the cytoplasmic localization and degradation of p53 in coordination with Hdm2. J Biol Chem 2006, 281:17457-17465.

10. Wan M, Cao X, Wu Y, Bai S, Wu L, Shi X, Wang N: Jab1 antagonizes TGFbeta signaling by inducing Smad4 degradation. EMBO Rep 2002, 3:171-176.

11. Bae MK, Ahn MY, Jeong JW, Bae MH, Lee YM, Bae SK, Park JW, Kim KR, Kim KW: Jab1 interacts directly with HIF-1alpha and regulates its stability. J Biol Chem 2002, 277:9-12.
12. Wei N, Deng XW: The COP9 signalosome. Annu Rev Cell Dev Biol 2003, 19:261-286.

13. Sui L, Dong Y, Ohno M, Watanabe Y, Sugimoto K, Tai Y, Tokuda M: Jab1 expression is associated with inverse expression of p27(kip1) and poor prognosis in epithelial overian tumors. Clin Cancer Res 2001, 7:4130-4135.

14. Kouvaraki MA, Tian L, Mansouri A, Zhang Q, Kumar R, Kittas C, Claret FX: Jun activation domain-binding protein 1 expression in breast cancer inversely correlates with the cell cycle inhibitor p27(Kip1). Cancer Res 2003, 63:2977-2981.

15. Rassidakis GZ, Claret FX, Lai R, Zhang Q, Sarris AH, McDonnell TJ, Medeiros L: Expression of p27(Kip1) and c-Jun activation binding protein 1 are inversely correlated in systemic anaplastic large cell lymphoma. Clin Cancer Res 2003, 9:1121-1128.

16. Shintani SLC, Mihara M, Hino S, Nakashiro K, Hamakawa H: Skp2 and Jab1 expression are associated with inverse expression of p27(KIP1) and poor prognosis in oral squamous cell carcinomas. Oncology 2003, 65:355-362.

17. Dong Y, Sui L, Watanabe Y, Yamaguchi F, Hatano N, Tokuda M: Prognostic significance of Jab1 expression in laryngeal squamous cell carcinomas. Clin Cancer Res 2005, 11:259-266.

18. Richardson KS, Zundel W: The emerging role of the COP9 signalosome in cancer. Mol Cancer Res 2005, 3:645-653.

19. Adler AS, Lin M, Horlings H, Nuyten DS, van de Vijver MJ, Chang HY: Genetic regulators of large-scale transcriptional signatures in cancer. Nat Genet 2006, 38:421-430.

20. Adler AS, Littlepage LE, Lin M, Kawahara TL, Wong DJ, Werb Z, Chang HY: CSN5 isopeptidase activity links COP9 signalosome activation to breast cancer progression. Cancer Res 2008, 68:506-515.

21. Hsu MC, Chang HC, Hung WC: HER-2/neu transcriptionally activates Jab1 expression via the AKT/beta-catenin pathway in breast cancer cells. Endocr Relat Cancer 2007, 14:655-667.

22. Mansouri A, Ridgway LD, Korapati AL, Zhang Q, Tian L, Wang Y, Siddik ZH, Mills GB, Claret FX: Sustained activation of JNK/p38 MAPK pathways in response to cisplatin leads to Fas ligand induction and cell death in ovarian carcinoma cells. J Biol Chem 2003, 278:19245-19256.

23. Nikolov DB, Burley SK: RNA polymerase II transcription initiation: a structural view. Proc Natl Acad Sci USA 1997, 94:15-22.

24. Numata A, Shimoda K, Kamezaki K, Haro T, Kakumitsu H, Shide K, Kato K, Miyamoto T, Yamashita Y, Oshima Y, Nakajima H, Iwama A, Aoki K, Takase K, Gondo H, Mano H, Harada M: Signal transducers and activators of transcription 3 augments the transcriptional activity of CCAAT/enhancerbinding protein alpha in granulocyte colony-stimulating factor signaling pathway. J Biol Chem 2005, 280:12621-12629.

25. Zahnow CA: CCAAT/enhancer binding proteins in normal mammary development and breast cancer. Breast Cancer Res 2002, 4:113-121.

26. Ramji DP, Foka P: CCAAT/enhancer-binding proteins: structure, function and regulation. Biochem J 2002, 365:561-575.

27. Grimm SL, Rosen JM: The role of C/EBPbeta in mammary gland development and breast cancer. J Mammary Gland Biol Neoplasia 2003, 8:191-204.

28. Bundy LM, Sealy L: CCAAT/enhancer binding protein beta (C/EBPbeta)-2 transforms normal mammary epithelial cells and induces epithelial to mesenchymal transition in culture. Oncogene 2003, 22:869-883.

29. Lowry JA, Mackay JP: GATA-1: one protein, many partners. Int I Biochem Cell Biol 2006, 38:6-11.

30. Crispino JD: GATA1 in normal and malignant hematopoiesis. Semin Cell Dev Biol 2005, 16:137-147.

31. Zahnow CA: CCAAT/enhancer-binding protein beta: its role in breast cancer and associations with receptor tyrosine kinases. Expert Rev Mol Med 2009, 11:e12.

32. Singh SP, Lipman J, Goldman H, Ellis FH, Aizenman L, Cangi MG, Signoretti S, Chiaur DS, Pagano M, Loda M: Loss or altered subcellular localization of p27 in Barrett's associated adenocarcinoma. Cancer Res 1998, 58:1730-1735.

33. Clevenger CV: Roles and regulation of stat family transcription factors in human breast cancer. Am J Pathol 2004, 165:1449-1460.

34. Horvath CM, Wen Z, Darnell JE Jr: A STAT protein domain that determines DNA sequence recognition suggests a novel DNA-binding domain. Genes Dev 1995, 9:984-994.

35. Xu X, Sun YL, Hoey T: Cooperative DNA binding and sequence-selective recognition conferred by the STAT amino-terminal domain. Science 1996, 273:794-797. 
36. Kaptein A, Paillard V, Saunders M: Dominant negative stat3 mutant inhibits interleukin-6-induced Jak-STAT signal transduction. J Biol Chem 1996, 271:5961-5964.

37. Yu CL, Meyer DJ, Campbell GS, Larner AC, Carter-Su C, Schwartz J, Jove R: Enhanced DNA-binding activity of a Stat3-related protein in cells transformed by the Src oncoprotein. Science 1995, 269:81-83.

38. Reddy EP, Korapati A, Chaturvedi P, Rane S: IL-3 signaling and the role of Src kinases, JAKs and STATs: a covert liaison unveiled. Oncogene 2000 19:2532-2547.

39. Eaton EM, Hanlon M, Bundy L, Sealy L: Characterization of C/EBPbeta isoforms in normal versus neoplastic mammary epithelial cells. J Cell Physiol 2001, 189:91-105.

40. Yu H, Jove R: The STATs of cancer-new molecular targets come of age. Nat Rev Cancer 2004, 4:97-105.

41. Irby RB, Yeatman TJ: Role of Src expression and activation in human cancer. Oncogene 2000, 19:5636-5642.

42. Aggarwal BB, Sethi G, Ahn KS, Sandur SK, Pandey MK, Kunnumakkara AB, Sung $\mathrm{B}$, Ichikawa $\mathrm{H}$ : Targeting signal-transducer-and-activator-oftranscription-3 for prevention and therapy of cancer: modern target but ancient solution. Ann N Y Acad Sci 2006, 1091:151-169.

doi:10.1186/bcr2902

Cite this article as: Shackleford et al:: Stat3 and CCAAT/enhancer binding protein beta (C/EBP-beta) regulate Jab1/CSN5 expression in mammary carcinoma cells. Breast Cancer Research 2011 13:R65.

\section{Submit your next manuscript to BioMed Central} and take full advantage of:

- Convenient online submission

- Thorough peer review

- No space constraints or color figure charges

- Immediate publication on acceptance

- Inclusion in PubMed, CAS, Scopus and Google Scholar

- Research which is freely available for redistribution

Submit your manuscript at www.biomedcentral.com/submit

C) Biomed Central 